\title{
Parameterization of middle atmospheric water vapor photochemistry for high-altitude NWP and data assimilation
}

\author{
J. P. McCormack ${ }^{1}$, K. W. Hoppel ${ }^{2}$, and D. E. Siskind ${ }^{1}$ \\ ${ }^{1}$ Space Science Division, Naval Research Laboratory, Washington DC, USA \\ ${ }^{2}$ Remote Sensing Division, Naval Research Laboratory, Washington DC, USA \\ Received: 4 June 2008 - Published in Atmos. Chem. Phys. Discuss.: 23 July 2008 \\ Revised: 4 November 2008 - Accepted: 17 November 2008 - Published: 16 December 2008
}

\begin{abstract}
This paper describes CHEM2D-H2O, a new parameterization of $\mathrm{H}_{2} \mathrm{O}$ photochemical production and loss based on the CHEM2D photochemical-transport model of the middle atmosphere. This parameterization accounts for the altitude, latitude, and seasonal variations in the photochemical sources and sinks of water vapor over the pressure region from $100-0.001 \mathrm{hPa}(\sim 16-90 \mathrm{~km}$ altitude). A series of free-running NOGAPS-ALPHA forecast model simulations offers a preliminary assessment of CHEM2D-H2O performance over the June 2007 period. Results indicate that the CHEM2D-H2O parameterization improves global 10day forecasts of upper mesospheric water vapor compared to forecasts using an existing one-dimensional (altitude only) parameterization. Most of the improvement is seen at high winter latitudes where the one-dimensional parameterization specifies photolytic $\mathrm{H}_{2} \mathrm{O}$ loss year round despite the lack of sunlight in winter. The new CHEM2D-H2O parameterization should provide a better representation of the downwelling of dry mesospheric air into the stratospheric polar vortex in operational analyses that do not assimilate middle atmospheric $\mathrm{H}_{2} \mathrm{O}$ measurements.
\end{abstract}

\section{Introduction}

Although the middle atmosphere $(15-100 \mathrm{~km}$ altitude) is extremely dry when compared to the troposphere, detailed knowledge of the water vapor distribution in this region is important for a number of reasons. For example, water vapor

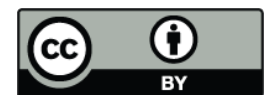

Correspondence to: J. P. McCormack (john.mccormack@nrl.navy.mil) abundance controls the availability of odd hydrogen species for catalytic ozone loss. In addition, the emission of longwave (terrestrial) radiation to space by water vapor is an important cooling process in the middle atmosphere. The relatively long photochemical lifetime of middle atmospheric water vapor also makes it a useful tracer for studying the dynamics of this region. Finally, the abundance of middle atmospheric water vapor is an important factor controlling the formation of both polar stratospheric clouds in winter and polar mesospheric (or noctilucent) clouds near the summer mesopause, the former being important for heterogeneous ozone loss. In more practical terms, water vapor is a fundamental prognostic variable in the dynamical cores of most numerical weather prediction (NWP) models. For these reasons, NWP and data assimilation (DA) systems whose top levels extend into the upper stratosphere and mesosphere require an accurate description of the photochemical sources and sinks of water vapor.

In general, operational requirements for timely forecasts prevent NWP systems from performing fully coupled photochemical model calculations because they are too computationally intensive. One solution to this problem is employ parameterizations based on linearization of the relevant photochemical processes (see, e.g. Cariolle and Dèqué, 1986). For a review of the development of linearized photochemistry parameterizations, see McCormack et al. (2006).

This paper describes a new linearized gas-phase water vapor photochemistry parameterization that is based on the CHEM2D zonally averaged photochemical-transport model of the middle atmosphere. CHEM2D has been successfully used to develop fast, accurate parameterizations of stratospheric ozone photochemistry (McCormack et al., 2004, 2006). MacKenzie and Harwood (2004) implemented this

Published by Copernicus Publications on behalf of the European Geosciences Union. 
(a) $\mathrm{CHEM} 2 \mathrm{D} \mathrm{CH}_{4}$ loss rates

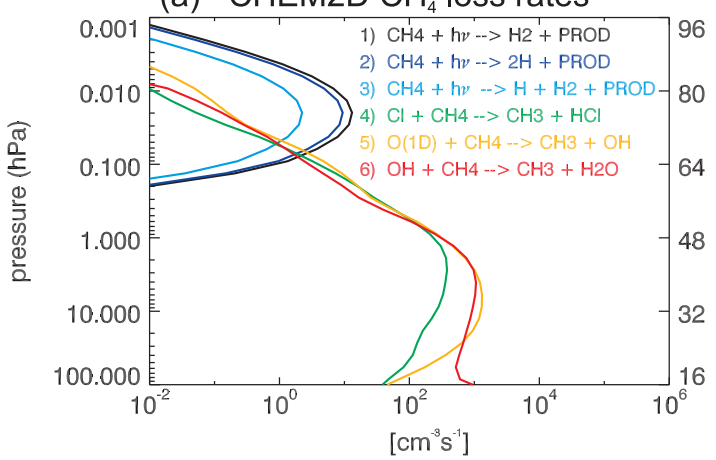

(b) $\mathrm{CHEM} 2 \mathrm{D} \mathrm{H}_{2} \mathrm{O}$ loss rates

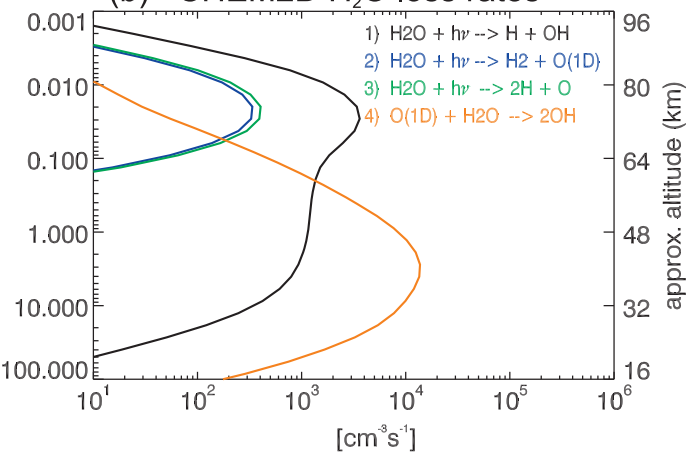

Fig. 1. Vertical profiles of the dominant CHEM2D model loss rates (molecules $\mathrm{cm}^{-3} \mathrm{~s}^{-1}$ ) at $5^{\circ} \mathrm{N}$ on $15 \mathrm{June}$ for $(\mathbf{a}) \mathrm{CH}_{4}$ and $(\mathbf{b}) \mathrm{H}_{2} \mathrm{O}$.

type of water vapor photochemistry parameterization in a general circulation model to study trends in middle atmospheric humidity. Here we apply a similar approach to provide a suitable representation of middle atmospheric water vapor for operational NWP/DA systems.

This new water vapor photochemistry parameterization, designated CHEM2D-H2O, has been recently implemented in the high-altitude version of the Navy Operational Global Atmospheric Prediction System (NOGAPS-ALPHA). Here we present a description of CHEM2D-H2O as well as results from a series of NOGAPS-ALPHA forecast model simulations designed to evaluate CHEM2D-H2O and compare its performance to a simpler one-dimensional (1-D) water vapor photochemistry scheme currently used in operational NWP/DA systems. The ultimate goal of this work is to provide global simulations of mesospheric water vapor accurate enough to identify the physical processes governing polar mesospheric cloud (PMC) formation near the summer mesopause. Section 2 gives a general overview of the CHEM2D model and middle atmospheric water vapor photochemistry. Section 3 describes the implementation of CHEM2D-H2O in NOGAPS-ALPHA. Section 4 examines middle atmospheric water vapor fields from a series of NOGAPS-ALPHA forecast model simulations to assess the performance of CHEM2D-H2O. Section 5 summarizes these results and outlines future research applications of CHEM2D-H2O.

\section{$2 \mathrm{H}_{2} \mathrm{O}$ photochemistry in the CHEM2D model}

CHEM2D is a zonally averaged (2-D) global model that features a fully self-consistent treatment of radiative, photochemical, and dynamical processes of the middle atmosphere (see, e.g., McCormack et al., 2006; McCormack et al., 2007). The model photochemistry accounts for reactions among 54 different species using reaction rates from Sander et al. (2003). CHEM2D extends from pole to pole with grid points spaced every $4.8^{\circ}$ in latitude; the vertical domain consists of 88 pressure levels from the surface to $p=6 \times 10^{-5} \mathrm{hPa}$ $(\sim 116 \mathrm{~km})$ spaced every $\sim 1.3 \mathrm{~km}$.

CHEM2D computes the solar UV heating above $40 \mathrm{~km}$ explicitly using the same spectral distribution of solar UV and absorption cross sections as in the model photolysis calculations. Details of the photolysis calculations can be found in Summers et al. (1997) and references therein. Modeled

$\mathrm{O}_{2}$ absorption in the Schumann-Runge bands is based on the parameterization of Minschwaner et al. (1993). $\mathrm{H}_{2} \mathrm{O}$ absorption is treated as in Siskind et al. (1994). $\mathrm{O}_{2}$ and $\mathrm{H}_{2} \mathrm{O}$ absorption at Lyman- $\alpha$ is based on the method of Lewis et al. (1983). The effects of $\mathrm{CH}_{4}$ absorption at Lyman- $\alpha$ on $\mathrm{H}_{2} \mathrm{O}$ are not considered. Solar cycle variations in irradiance are specified from 1200-8000 Åbased on the measurements of Lean et al. (1997). The CHEM2D photolysis rates reported here are for solar minimum conditions. The Lyman- $\alpha$ irradiance at solar minimum was taken to be $3 \times 10^{11}$ photons $\mathrm{cm}^{-1} \mathrm{~s}^{-1}$.

Water vapor $\left(\mathrm{H}_{2} \mathrm{O}\right)$ in the middle atmosphere is produced directly through oxidation of stratospheric methane $\left(\mathrm{CH}_{4}\right)$ by the hydroxyl radical $\left(\mathrm{OH}+\mathrm{CH}_{4} \rightarrow \mathrm{H}_{2} \mathrm{O}+\mathrm{CH}_{3}\right)$ and indirectly through a series of reactions involving the methyl radical $\left(\mathrm{CH}_{3}\right)$. The net effect is that approximately two $\mathrm{H}_{2} \mathrm{O}$ molecules are produced for each $\mathrm{CH}_{4}$ molecule lost in the stratosphere (e.g., LeTexier et al., 1988, and references therein). Consequently, the total number density of hydrogen throughout much of the stratosphere $Q=2\left[\mathrm{CH}_{4}\right]+\left[\mathrm{H}_{2} \mathrm{O}\right]$ is a constant (neglecting the relatively small amount of molecular hydrogen, $\mathrm{H}_{2}$ ). This relationship can be used to express stratospheric $\mathrm{H}_{2} \mathrm{O}$ production in terms of $\mathrm{H}_{2} \mathrm{O}$ abundance, which is advantageous since it eliminates the need for a prognostic $\mathrm{CH}_{4}$ variable.

Figure 1a plots vertical profiles of individual CHEM2D $\mathrm{CH}_{4}$ loss rates (molecules $\mathrm{cm}^{-3} \mathrm{~s}^{-1}$ ) at $5^{\circ} \mathrm{N}$ on 15 June. Reactions (5) and (6) listed in Fig. 1a are the key reactions 

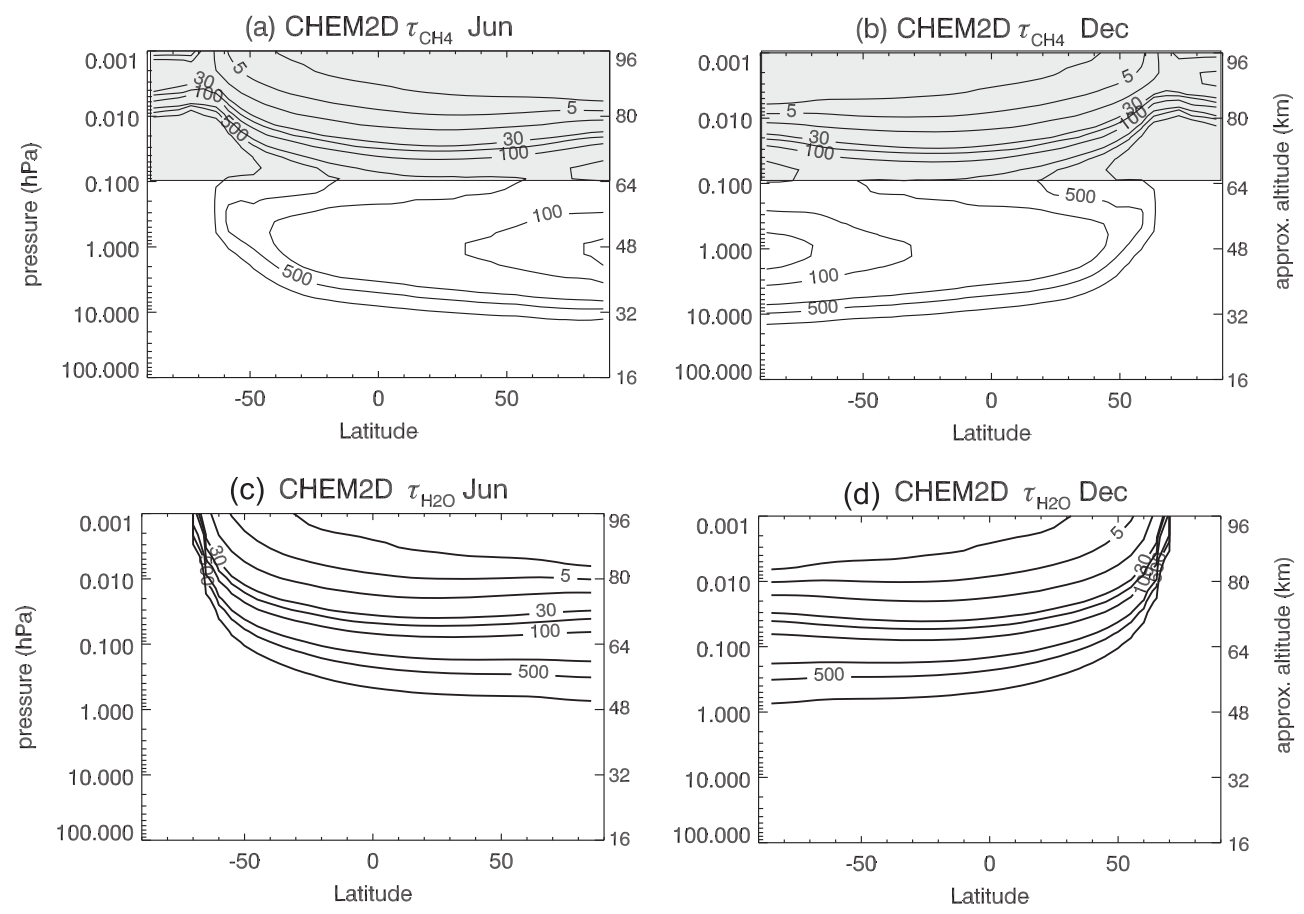

Fig. 2. Pressure-latitude plots of $\mathrm{CHEM} 2 \mathrm{D} \mathrm{CH} 4$ photochemical lifetimes (in days) for (a) 15 June and (b) 15 December, and of CHEM2D $\mathrm{H}_{2} \mathrm{O}$ lifetimes for (c) 15 June and (d) 15 December. Shading in (a) and (b) indicates region where $\mathrm{CH}_{4}$ loss is primarily through photolysis. Contours are drawn at $3,5,10,30,50,100,300,500$, and 1000 days.

responsible for stratospheric $\mathrm{H}_{2} \mathrm{O}$ production. Above the $0.1 \mathrm{hPa}$ level, $\mathrm{CH}_{4}$ loss occurs through photolysis and does not produce $\mathrm{H}_{2} \mathrm{O}$ directly.

As a result total hydrogen $Q$ is not conserved in the mesosphere. Middle atmospheric $\mathrm{H}_{2} \mathrm{O}$ is destroyed primarily through photolysis in the mesosphere by solar UV and Lyman- $\alpha$ radiation, yielding a number of different byproducts depending on the energy of the incoming radiation (Steif et al., 1975). $\mathrm{H}_{2} \mathrm{O}$ is lost in the stratosphere through reaction with atomic oxygen. Figure $1 \mathrm{~b}$ plots individual CHEM2D vertical profiles of $\mathrm{H}_{2} \mathrm{O}$ loss rates at $5^{\circ} \mathrm{N}$ on 15 June. The loss rates for the photolysis Reactions 13 in Fig. $1 \mathrm{~b}$ are based on estimated quantum yields of 0.78 , 0.10 , and 0.12 , respectively. These values of the quantum yields were determined from a synthesis of available laboratory measurements (Steif et al., 1975; Harich et al., 2000).

Photochemical loss rates are commonly used to infer an effective photochemical lifetime, which is a convenient way to quantify the relevant time scales for photochemistry relative to other physical processes such as advection. Figure 2 plots CHEM2D photochemical lifetimes of $\mathrm{CH}_{4}$ and $\mathrm{H}_{2} \mathrm{O}$ ( $\tau_{\mathrm{CH} 4}$ and $\tau_{\mathrm{H} 2 \mathrm{O}}$ respectively) for June and December conditions throughout the middle atmosphere. The lifetimes are computed from the sum of the individual loss rates as

$\tau_{\mathrm{CH}_{4}}=\frac{\left[\mathrm{CH}_{4}\right]}{\sum_{i=1}^{6} L_{i}}, \quad \tau_{\mathrm{H}_{2} \mathrm{O}}=\frac{\left[\mathrm{H}_{2} \mathrm{O}\right]}{\sum_{i=1}^{4} L_{i}}$ where $\left[\mathrm{CH}_{4}\right]$ and $\left[\mathrm{H}_{2} \mathrm{O}\right]$ denote $\mathrm{CHEM} 2 \mathrm{D} \mathrm{CH}_{4}$ and $\mathrm{H}_{2} \mathrm{O}$ abundances (molecules $\mathrm{cm}^{-3}$ ) and $L_{i}$ is the loss rate (molecules $\mathrm{cm}^{-3} \mathrm{~s}^{-1}$ ) for the individual reactions in Fig. 1 .

Figures $2 \mathrm{a}$ and $\mathrm{b}$ show that the shortest $\mathrm{CH}_{4}$ lifetimes $(<2$ days) are in the summer mesopause region where photolysis is the dominant loss mechanism. A secondary minimum in $\tau_{\mathrm{CH} 4}$ is seen near the summer polar stratopause due to rapid $\mathrm{CH}_{4}$ loss via reaction with chlorine (Reaction 4 in Fig. 1).

The shaded regions in Fig. 2 indicate where $\mathrm{CH}_{4}$ loss is dominated by photolysis, a process that does not directly produce $\mathrm{H}_{2} \mathrm{O}$. The unshaded regions of Fig. $2 \mathrm{a}$ and $\mathrm{b}$ indicate where $\mathrm{CH}_{4}$ loss produces $\mathrm{H}_{2} \mathrm{O}$ in the stratosphere via Reactions 5 and 6 as in Fig 1a.

Values of $\tau_{\mathrm{CH} 4}$ for levels below $0.1 \mathrm{hPa}$ exceed 50 days, indicating that stratospheric $\mathrm{H}_{2} \mathrm{O}$ production is slow compared to typical transport timescales. As a result, including the effects of this process in typical NWP/DA systems issuing 5- to 10-day forecasts is not crucial provided that accurate stratospheric humidity data are being regularly assimilated globally. In the absence of such data, or when conducting longer free-running model simulations for seasonal prediction or climate simulations, the contribution of $\mathrm{CH}_{4}$ oxidation to $\mathrm{H}_{2} \mathrm{O}$ production becomes more significant.

Fig. $2 \mathrm{c}$ and $\mathrm{d}$ show that values of $\tau_{\mathrm{H} 2 \mathrm{O}}$ in the summer hemisphere are less than 5 days above the $0.01 \mathrm{hPa}$ level, indicating that $\mathrm{H}_{2} \mathrm{O}$ photolysis is an important effect for 

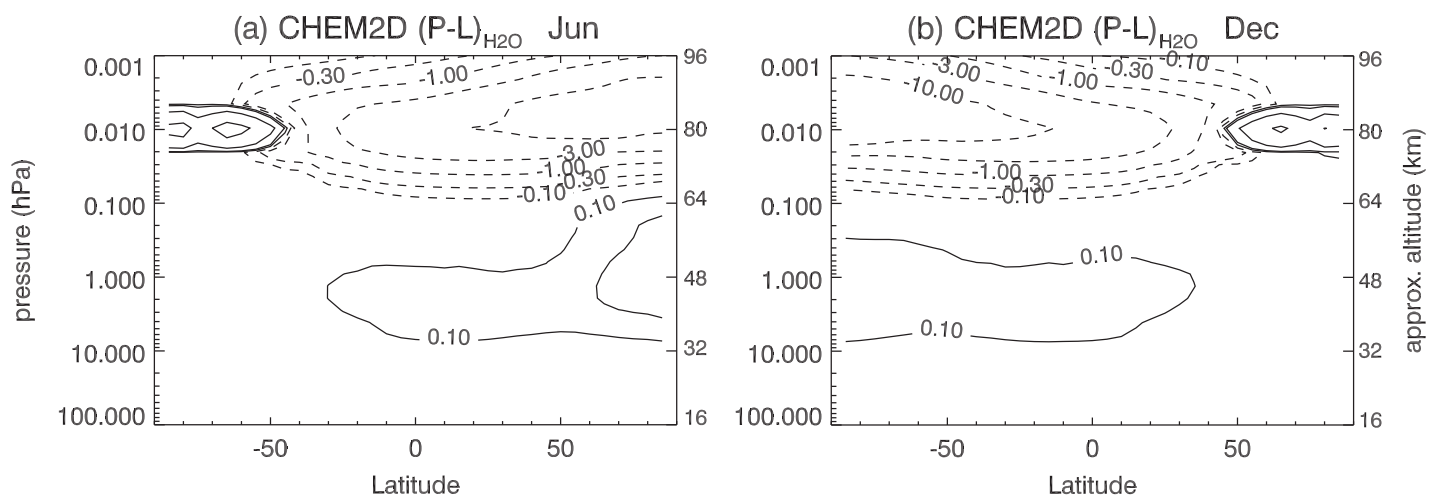

Fig. 3. Pressure-latitude plots of net CHEM2D middle atmosphere water vapor photochemical tendency $(P-L)_{\mathrm{H} 2 \mathrm{O}}$ for (a) 15 June and (b) 15 December in parts per million (volume) per month. Contours are drawn at $\pm 0.1, \pm 0.3, \pm 1, \pm 3$, and \pm 10 ppmv per month. Dashed contours denote negative values.

accurate medium-range forecasts in this region. Values of $\tau_{\mathrm{H} 2 \mathrm{O}}$ near the mesopause increase rapidly poleward of $50^{\circ}$ latitude in winter as the amount of sunlight diminishes.

To highlight the latitude, altitude, and seasonal dependences of $\mathrm{H}_{2} \mathrm{O}$ photochemistry in the middle atmosphere, Fig. 3 plots the net CHEM2D photochemical tendency for water vapor, $(P-L)_{\mathrm{H} 2 \mathrm{O}}$, in parts per million by volume (ppmv) per month as a function of latitude and pressure for 15 June and 15 December, where $P$ is the net production rate and $L$ is the net loss rate. In the stratosphere, $(P-L)_{\mathrm{H} 2 \mathrm{O}}$ is weakly positive as a result of relatively slow $\mathrm{H}_{2} \mathrm{O}$ production through $\mathrm{CH}_{4}$ oxidation in the absence of water vapor photolysis at these altitudes (see Figs. 1 and 2). In the mesosphere, $(P-L)_{\mathrm{H} 2 \mathrm{O}}$ is mostly negative due to photolytic loss, with the largest loss rates occurring near the summer mesopause region. The positive values of $(P-L)_{\mathrm{H} 2 \mathrm{O}}$ in the winter hemisphere near $80 \mathrm{~km}$ poleward of $50^{\circ}$ latitude are the result of enhanced $\mathrm{H}_{2} \mathrm{O}$ production via the reaction $\mathrm{OH}+\mathrm{HO}_{2} \rightarrow \mathrm{H}_{2} \mathrm{O}+\mathrm{O}_{2}$. This enhancement is due to poleward transport of odd hydrogen from sunlit latitudes into polar night, where it becomes long-lived in the upper mesosphere (Brasseur and Solomon, 1986).

The values of $\tau_{\mathrm{CH} 4}, \tau_{\mathrm{H} 2 \mathrm{O}}$, and $(P-L)_{\mathrm{H} 2 \mathrm{O}}$ presented in this section, which vary with latitude, altitude, and month, serve as the basis for the new CHEM2D- $\mathrm{H}_{2} \mathrm{O}$ parameterization. CHEM2D- $\mathrm{H}_{2} \mathrm{O}$ differs from the water vapor photochemistry parameterization currently used in the European Centre for Medium Range Weather Forecasts (ECMWF) Integrated Forecast system (IFS) (Untch and Simmons, 1999; ECMWF, 2006; Feist et al., 2007), which parameterizes production via stratospheric $\mathrm{CH}_{4}$ oxidation and loss via mesospheric photolysis as a function of altitude only, neglecting possible latitude and seasonal dependences. This method expresses the water vapor photochemical tendency as $\frac{\partial r}{\partial t}=k_{1}\left(r_{Q}-r\right)-k_{2} r$

where $r$ is the local water vapor mixing ratio and $r_{Q}$ is the equivalent total hydrogen mixing ratio.

The coefficients $k_{1}$ and $k_{2}$ are determined from analytical fits to quoted values of $\tau_{\mathrm{CH} 4}$ in the stratosphere and $\tau_{\mathrm{H} 2 \mathrm{O}}$ in the mesosphere, respectively, at various altitudes from Brasseur and Solomon (1986).

The coefficients $k_{1}$ and $k_{2}$ vary with altitude and are constant with latitude and season. It is assumed that $r_{Q}$ has a constant value of $6.8 \mathrm{ppmv}$ based on the results of Randel et al. (1998). Figure 4 plots CHEM2D values of $r_{Q}$ showing this assumption holds for most of the stratosphere except winter polar regions where downward transport of dry mesospheric air occurs (LeTexier et al., 1988; Randel et al., 1998). Thus the ECMWF scheme provides a reasonable 1-D photochemical constraint on global stratospheric $\mathrm{H}_{2} \mathrm{O}$, but may overestimate stratospheric $\mathrm{H}_{2} \mathrm{O}$ production in regions where conservation of $r_{Q}$ breaks down.

To compare this 1D approach to the CHEM2D-H2O parameterization, Fig. 5 plots the vertical profile of the combined photochemical lifetime, $\left(k_{1}+k_{2}\right)^{-1}$ from the ECMWF scheme (ECMWF, 2006) along with CHEM2D values of $\tau_{\mathrm{CH} 4}$ and $\tau_{\mathrm{H} 2 \mathrm{O}}$ over the equator for each month of the year. Only CHEM2D values of $\tau_{\mathrm{CH} 4}$ below the $0.1 \mathrm{hPa}$ level are plotted in Fig. 5, since it is in this region where $\mathrm{CH}_{4}$ loss leads to $\mathrm{H}_{2} \mathrm{O}$ production. Also plotted in Fig. 5 are values of the combined CHEM2D lifetime

$$
\tau^{*}=\frac{1}{\tau_{\mathrm{CH} 4}^{-1}+\tau_{\mathrm{H} 2 \mathrm{O}}^{-1}}
$$

for each month, which are determined from the plotted values of $\tau_{\mathrm{CH} 4}$ and $\tau_{\mathrm{H} 2 \mathrm{O}}$ in Fig. 5.

The quantity $\tau^{*}$ provides a single, concise description of the time scale for $\mathrm{H}_{2} \mathrm{O}$ photochemistry throughout the middle atmosphere that varies with latitude and season analogous to 
(a) CHEM2D $r_{Q}$ June

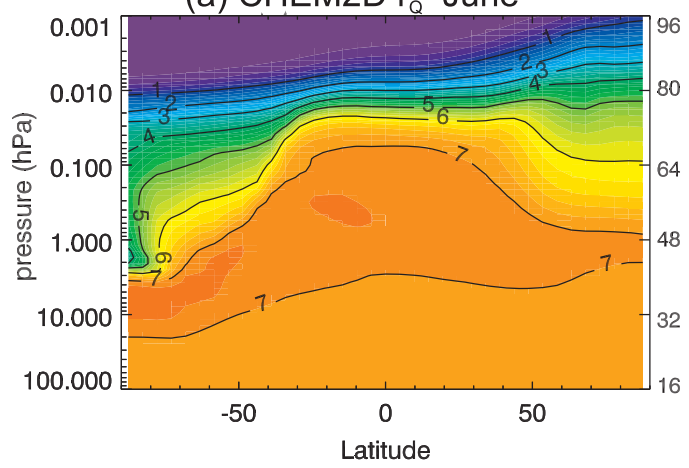

(b) CHEM2D $r_{Q}$ December

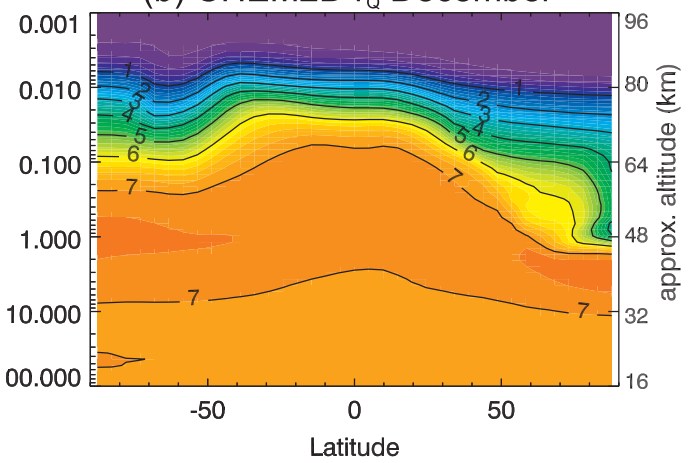

Fig. 4. Pressure-latitude plots of total hydrogen $r_{Q}$ (in ppmv) from the CHEM2D model for (a) 15 June and (b) 15 December. Contours are drawn every 1 ppmv.

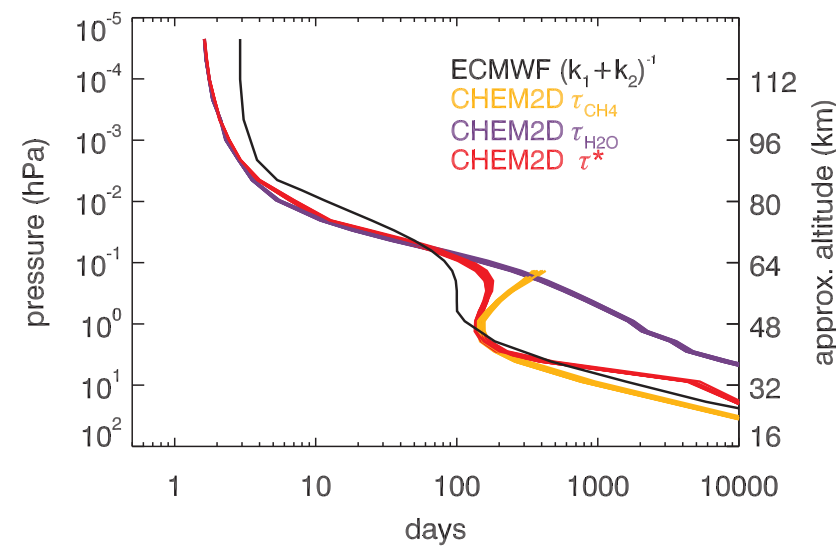

Fig. 5. Comparison of combined photochemical lifetime (days) in the ECMWF water vapor photochemistry parameterization (black curve) with CHEM2D lifetimes $\tau_{\mathrm{H} 2 \mathrm{O}}$ (purple curves), $\tau_{\mathrm{CH} 4}$ (gold curves), $\tau^{*}$ (red curves) for all 12 months over the equator. The CHEM2D $\tau_{\mathrm{CH} 4}$ profile is only plotted at levels where $\mathrm{CH}_{4}$ oxidation is the dominant loss process (c.f., Fig. 1 and unshaded region in Fig. 2).

the 1-D profile of $\left(k_{1}+k_{2}\right)^{-1}$ in the ECMWF scheme. The overlapping curves in Fig. 5 indicate that there is virtually no seasonal dependence in the $\mathrm{H}_{2} \mathrm{O}$ production and loss terms at low latitudes, in agreement with Figs. 2 and 3. As a result, CHEM2D values of $\tau^{*}$ for all 12 months closely match the 1D scheme's $k_{1}^{-1}$ and $k_{2}^{-1}$ profile.

At higher latitudes, however, seasonal variations in $\tau_{\mathrm{H} 2 \mathrm{O}}$ and $\tau_{\mathrm{CH} 4}$ are both quite large. As a result, $\tau^{*}$ also exhibits large seasonal variations at higher latitudes. To illustrate this point, Figure 6 compares values of $\left(k_{1}+k_{2}\right)^{-1}$ from the ECMWF scheme with values of $\tau^{*}$ at $70^{\circ} \mathrm{N}$ for March, June, September, and December.

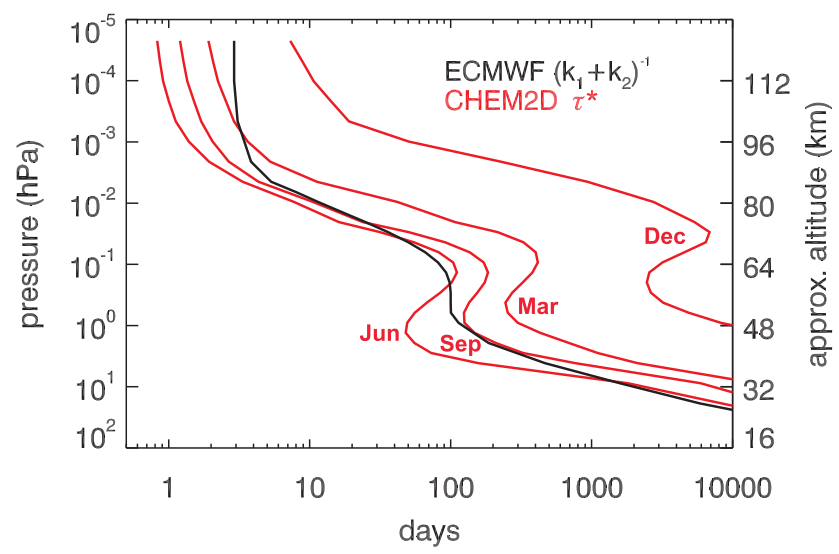

Fig. 6. Comparison of combined photochemical lifetime (days) in the ECMWF water vapor photochemistry parameterization (black curve) with values of the CHEM2D effective lifetime $\tau^{*}$ (red curves) at $70^{\circ} \mathrm{N}$ on the 15 th day of March, June, September, and December.

The CHEM2D model results presented in this section demonstrate that the net middle atmospheric $\mathrm{H}_{2} \mathrm{O}$ photochemical tendency exhibits pronounced latitude and seasonal variations that should be accounted for in NWP/DA systems extending into the mesosphere. The CHEM2D-H2O parameterization described in the following section accounts for these variations.

\section{CHEM2D-H2O in NOGAPS-ALPHA}

This section describes the CHEM2D-H2O parameterization and its implementation in NOGAPS-ALPHA. First, we briefly describe the NOGAPS-ALPHA forecast model and data assimilation components. We then provide a detailed description of the CHEM2D-H2O scheme as it is currently used in NOGAPS-ALPHA. 


\subsection{NOGAPS-ALPHA description}

The high-altitude NOGAPS-ALPHA NWP/DA system (Hoppel et al., 2008) is capable of assimilating middle atmosphere constituent measurements such as $\mathrm{H}_{2} \mathrm{O}$ profiles obtained from the NASA EOS Aura Microwave Limb Sounder (MLS) (Eckermann et al., 2008, referred to hereafter as E2008). The 68-level (L68) NOGAPS-ALPHA global spectral forecast model (GSFM) initializes and advects specific humidity $q$ at all levels from the surface to its top at $5 \times 10^{-4} \mathrm{hPa}$. The $q$ fields are initialized using traditional meteorological analyses from the surface up to the $200 \mathrm{hPa}$ level. Above this level, the humidity fields can be initialized using either assimilated water vapor measurements for a specific date or a zonal monthly mean climatology based on measurements from the Upper Atmospheric Research Satellite (UARS) Halogen Occultation (HALOE) and MLS instruments (Randel et al., 1998; Grooß and Russell, 2005), depending on the application.

Parameterizations for moist physics in NOGAPS-ALPHA are identical to those used in the operational version of NOGAPS (Hogan and Rosmond, 1991). These include shallow cumulus mixing (Tiedtke, 1984), deep cumulus convection (Peng et al., 2004), and convective, stratiform, and boundary layer cloud formation and precipitation (Slingo, 1987; Teixeira and Hogan, 2002). For a more complete description of NOGAPS-ALPHA model physics, see McCormack et al. (2006) and E2008. Since they are designed primarily for tropospheric applications, the model's moist physics routines are only employed from the surface up to the $50 \mathrm{hPa}$ level $(\sim 20 \mathrm{~km})$. In the stratosphere and mesosphere, parameterized water vapor photochemical production and loss constrain the NOGAPS-ALPHA $q$ fields. Without this photochemical constraint, upwelling of stratospheric air into the mesosphere would produce unrealistically high values of mesospheric humidity over forecast periods of 2-3 days. This would pose a problem for accurate forecasts of mesospheric humidity, especially in regions where humidity measurements are not assimilated.

All forecast model results in this study employ triangular truncation of the first 79 wavenumbers (T79), with a horizontal grid spacing of $1.5^{\circ}$ in longitude and latitude on the quadratic Gaussian grid. The model uses the non-orographic gravity wave drag parameterization of Garcia et al. (2007) with the same settings as in E2008. The T79L68 model is initialized with analyzed winds, temperature, and constituents (e.g., $\mathrm{O}_{3}$ and $\mathrm{H}_{2} \mathrm{O}$ ) produced by the NOGAPS-ALPHA DA component, which is described in detail by Hoppel et al. (2008) and E2008. From the surface to the mid-stratosphere, these NOGAPS-ALPHA analyses are based on assimilation of conventional meteorological data sets used by the operational T239L30 system.

For the June 2007 period studied here, NOGAPS-ALPHA assimilates Aura MLS temperature, $\mathrm{O}_{3}$, and $\mathrm{H}_{2} \mathrm{O}$ profiles (Froidevaux et al., 2006), as well as temperatures from the
Sounding of the Atmosphere Using Broadband Radiometry (SABER) instrument on the Thermosphere Ionosphere Mesosphere Energetics and Dynamics (TIMED) satellite (Kutepov et al., 2006), up to the $0.002 \mathrm{hPa}$ level, (E2008). Above this level, model fields are initialized with climatology as in McCormack et al. (2006). The altitude resolution of the MLS water vapor retrievals decreases significantly with increasing altitude (Lambert et al., 2007). A Gaussian averaging kernel in the vertical direction with a full-width at half maximum value of $2 \mathrm{~km}$ is applied to the assimilated MLS water vapor profiles. This was done to constrain the analysis to the low resolution MLS profiles rather than risk introducing any spurious vertical structure in the $\mathrm{H}_{2} \mathrm{O}$ fields that may arise in data-poor regions. The background error variance for water vapor in the upper atmosphere was set large enough to ensure that the analysis was highly constrained to the observations, producing a zonal mean distribution that is nearly identical to the MLS data. For further details of the assimilation system, see Hoppel et al. (2008).

A comprehensive evaluation of the NOGAPS middle atmospheric data assimilation system, including comparisons with independent observations, is currently underway. The purpose of this paper is to introduce the CHEM2D-H2O photochemistry parameterization and evaluate its performance based on NOGAPS-ALPHA forecast model simulations of middle atmospheric water vapor. The following section describes the implementation of CHEM2D-H2O in NOGAPSALPHA.

\subsection{The CHEM2D-H2O parameterization}

The CHEM2D-H2O parameterization in NOGAPS-ALPHA expresses the local time rate of change of the $\mathrm{H}_{2} \mathrm{O}$ mixing ratio $r$ as the difference between the zonally averaged production and loss rates computed with the CHEM2D model (see Fig. 3):

$$
\frac{\partial r}{\partial t}=(P-L)_{\mathrm{H} 2 \mathrm{O}} .
$$

Although specific humidity $q$ is the NOGAPS-ALPHA model's prognostic variable, for the sake of consistency with the photochemical parameterization in Eq. (2) we will use volume mixing ratio $r$ as the moisture variable in the following discussion. Model mixing ratio $r$ is related to $q$ through the relation

$r=\frac{M_{d}}{M_{w}} \frac{q}{1-q}$

where $M_{d}$ and $M_{w}$ are the molecular weights of dry air and $\mathrm{H}_{2} \mathrm{O}$, respectively.

We assume that $(P-L)_{\mathrm{H} 2 \mathrm{O}}$ is primarily a function of $r$. In the mesosphere, this assumption is justified because the loss rate due to photolysis is directly proportional to the local $\mathrm{H}_{2} \mathrm{O}$ mixing ratio. In the stratosphere, where the production rates via methane oxidation depend on the local $\mathrm{CH}_{4}$ mixing 
(a) CHEM2D $\tau^{*}$ Jun

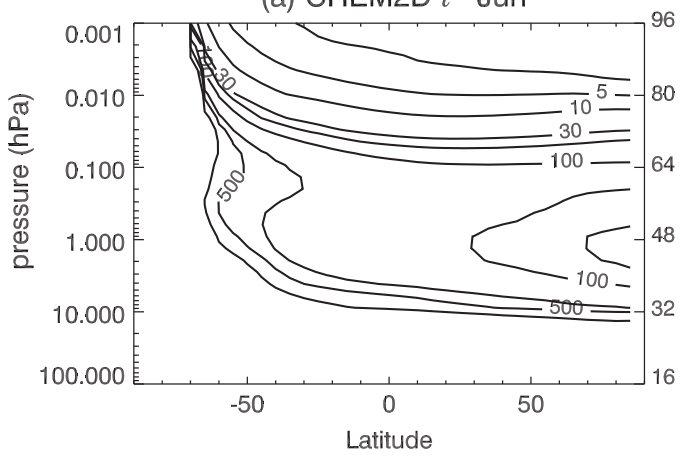

(b) CHEM2D $\tau^{*}$ Dec

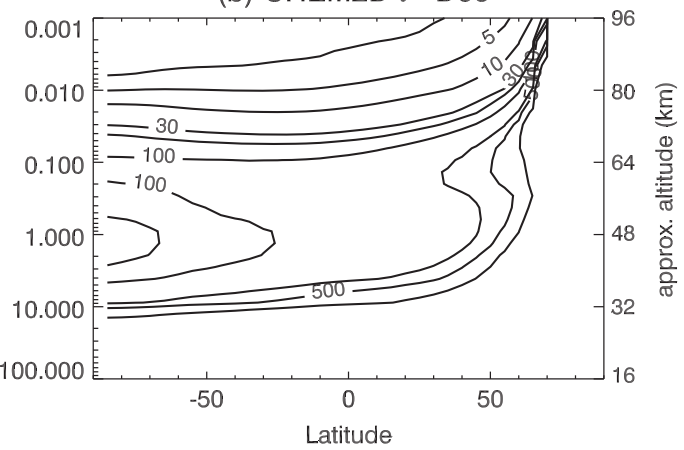

Fig. 7. Pressure-latitude plots of the effective photochemical lifetime $\tau^{*}$ (days) used in the CHEM2D-H2O parameterization for (a) 15 June and (b) 15 December.

ratio, this assumption holds where the local $\mathrm{H}_{2} \mathrm{O}$ mixing ratio can be expressed in terms of the $\mathrm{CH}_{4}$ mixing ratio through the approximate conservation of $r_{Q}$ (see Fig. 4). Where the assumption of $r_{Q}$ conservation breaks down, i.e., in the winter polar stratosphere, CHEM2D values of $\tau_{\mathrm{CH} 4}$ exceed 100 days. As shown below, accounting for these latitude and seasonal variations in $\mathrm{H}_{2} \mathrm{O}$ production and loss ensures that the CHEM2D-H2O parameterization only introduces photochemical tendencies in regions where its underlying assumptions are valid.

The function $(P-L)_{\mathrm{H} 2 \mathrm{O}}[r]$ can be approximated using a first-order Taylor series expansion about a reference state such that

$\frac{\partial r(\lambda, \phi, p, t)}{\partial t}=(P-L)_{\mathrm{H} 2 \mathrm{O}}^{o}+\left.\frac{\partial(P-L)_{\mathrm{H} 2 \mathrm{O}}}{\partial r}\right|_{o}\left(r-r^{o}\right)$

where $\lambda$ is longitude, $\phi$ is latitude, $p$ is pressure, and " $o$ " denotes the reference state.

We proceed by assuming that Eq. (6) yields an equilibrium (reference) state $r^{o}$ that is the net balance between photochemical production and loss, such that any deviations from this state can be treated as small perturbations about that reference state. This follows the method used in linearized ozone photochemistry schemes, as reviewed by McCormack et al. (2006) and Lahoz et al. (2007).

Applying the expansion Eq. (6) to the ECMWF relation Eq. (2), it is straightforward to show that

$$
\begin{aligned}
(P-L)_{H_{2} O}^{o} & =k_{1}\left(r_{Q}-r^{o}\right)-k_{2} r^{o}, \\
\left.\frac{\partial(P-L)_{H_{2} O}^{o}}{\partial r}\right|_{o} & =-\left(k_{1}+k_{2}\right)
\end{aligned}
$$

illustrating that this approach is mathematically consistent with the 1-D parameterization in Eq. (2).

As discussed in Sect. 2 and illustrated in Figs. 5 and 6, the CHEM2D-H2O analog of Eq. (8) is

$\left.\frac{\partial(P-L)_{\mathrm{H}_{2} \mathrm{O}}^{o}}{\partial r}\right|_{o}=-\left(\tau^{*}\right)^{-1}$ where $\tau^{*}$ represents the combined time scales for $\mathrm{H}_{2} \mathrm{O}$ production via $\mathrm{CH}_{4}$ oxidation in the stratosphere and $\mathrm{H}_{2} \mathrm{O}$ photolysis in the mesosphere. CHEM2D model values of $\tau^{*}$ are tabulated as a function of latitude, pressure and season and then interpolated in space and time to the NOGAPS-ALPHA forecast model grid. Figure 7 plots the latitude and altitude dependence of $\tau^{*}$ for June and December conditions.

The analytical ECMWF expression Eq. (7) assumes constant total hydrogen $r_{Q}=6.8 \mathrm{ppmv}$ at all altitudes. As illustrated in Fig. 4, this assumption breaks down in the upper stratosphere and mesosphere. In addition, $\mathrm{CH}_{4}$ oxidation becomes a negligible source of $\mathrm{H}_{2} \mathrm{O}$ in the mesosphere. Thus, for CHEM2D-H2O we instead derive $(P-L)_{\mathrm{H}_{2} \mathrm{O}}^{o}$ values as a function of latitude, pressure and season directly from the CHEM2D model, examples of which were shown previously in Fig. 3. This approach enables us to compute equilibrium rates without any explicit reference to total hydrogen, and thus to extend these rates into the mesosphere where total hydrogen conservation breaks down and is dominated by photolytic loss.

Adopting an approach similar to that for the CHEM2D ozone photochemistry parameterization, or CHEM2D-OPP (McCormack et al., 2006), the specific humidity photochemical tendency in NOGAPS-ALPHA is applied by first defining a photochemical steady state value for the water vapor mixing ratio

$r^{s s}=r^{o}+(P-L)^{o} \tau^{*}$

so that the $\mathrm{H}_{2} \mathrm{O}$ mixing ratio tendency can be expressed as

$\frac{\partial r}{\partial t}=\frac{-\left(r-r^{s s}\right)}{\tau^{*}}$.

The updated mixing ratio value is computed using a standard backward-Euler solution of the form

$r(t+\Delta t)=r(t)+\left[r^{s s}-r(t)\right]\left[\frac{\frac{\Delta t}{\tau^{*}}}{1+\frac{\Delta t}{\tau^{*}}}\right]$

and then converted to specific humidity using Eq. (5). 


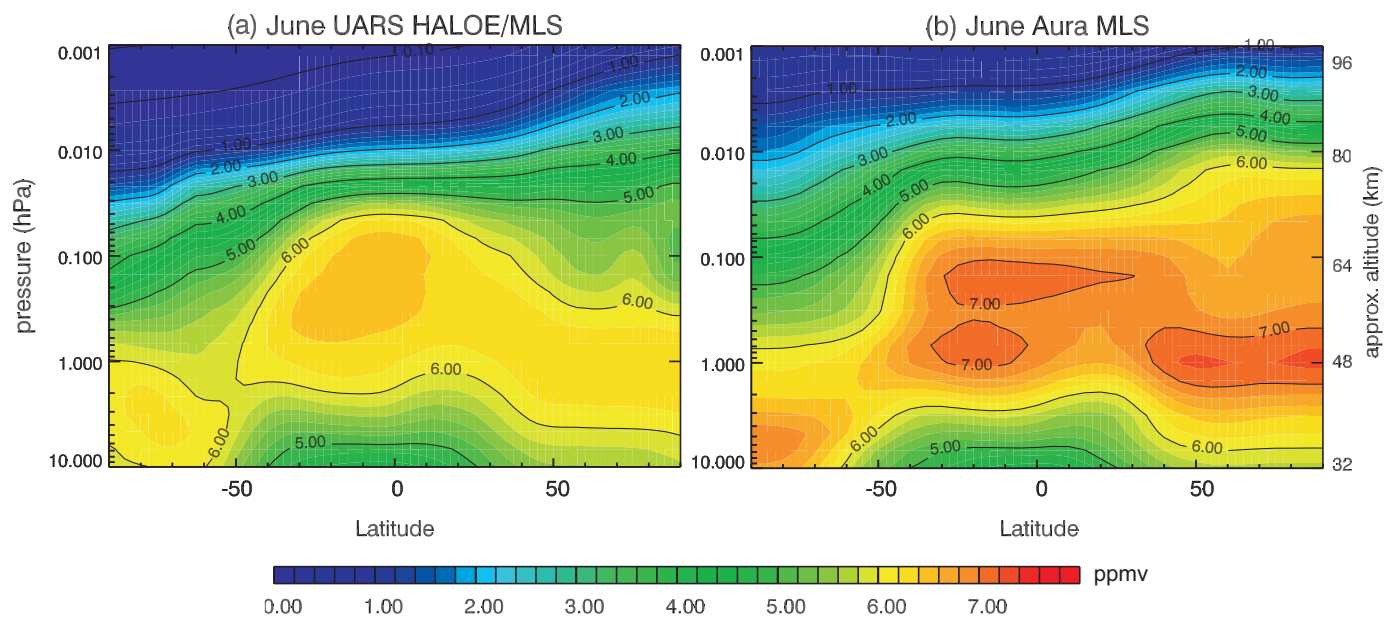

Fig. 8. Pressure-latitude plots of the zonal mean reference state $\mathrm{H}_{2} \mathrm{O}$ mixing ratio $r^{o}$ (in ppmv) for June based on (a) the combined UARS HALOE/MLS climatology used in EXP1 and (b) the Aura MLS climatology used in EXP2.

Table 1. $\mathrm{H}_{2} \mathrm{O}$ photochemistry parameterizations used in the NOGAPS-ALPHA forecast model simulations.

\begin{tabular}{|c|c|}
\hline Experiment Name & Description \\
\hline EXP1 & $\begin{array}{l}\text { CHEM2D-H2O with } r^{o} \\
\text { based on UARS HALOE/MLS }\end{array}$ \\
\hline EXP2 & $\begin{array}{l}\text { CHEM2D-H2O with } r^{o} \\
\text { based on Aura MLS }\end{array}$ \\
\hline EXP3 & ECMWF \\
\hline
\end{tabular}

In theory, the reference state mixing ratio $r^{o}$ should correspond to the CHEM2D model mixing ratio at photochemical equilibrium. In practice, values of $r^{o}(\phi, p, t)$ are often specified using an observation-based climatology of middle atmospheric water vapor. Based on earlier experience with linearized ozone photochemistry parameterizations (McCormack et al., 2006; Geer et al., 2007; Coy et al., 2007), use of an observation-based reference state ensures that the linearized photochemical tendency terms will not produce large biases between the modeled and assimilated constituent values, which can negatively impact forecast skill. In this study, we perform a similar evaluation of the CHEM2D-H2O parameterization's sensitivity to the assumed background state using two different $r^{o}$ distributions. The first is based on monthly zonal mean MLS/HALOE climatology (Randel et al., 1998; Grooß and Russell, 2005) between 100-0.01 hPa combined with CHEM2D model values above the $0.01 \mathrm{hPa}$ level. The second combines June zonal mean Aura MLS $\mathrm{H}_{2} \mathrm{O}$ mixing ratios averaged over the years 2005-2008 up to the $0.002 \mathrm{hPa}$ level with CHEM2D model values above this level. Solar UV fluxes in the CHEM2D model were set to solar minimum levels following Lean et al. (1997) to match June 2007 conditions.
Figure 8 compares these two $r^{o}$ distributions. The Aura MLS $\mathrm{H}_{2} \mathrm{O}$ mixing ratios in Fig. $8 \mathrm{~b}$ are generally higher than the UARS-based values in Fig. 8a throughout the Northern Hemisphere extratropical upper mesosphere. The results presented in the following section demonstrate how these differences can affect 10-day forecasts of middle atmospheric $\mathrm{H}_{2} \mathrm{O}$.

\section{Results}

Table 1 lists three sets of NOGAPS-ALPHA forecast model simulations, designated EXP1, EXP2, and EXP3, used to evaluate the new CHEM2D-H2O parameterization. EXP1 employs CHEM2D-H2O with the UARS-based $r^{o}$ for the month of June (see Fig. 8a). EXP2 employs CHEM2D$\mathrm{H} 2 \mathrm{O}$ with the Aura MLS-based $r^{o}$ for June (Fig. 8b). EXP3 uses the 1D water vapor photochemistry parameterization (2) currently used in the operational ECMWF IFS. These three sets of simulations each consist of five 10-day forecasts initialized on 5, 10, 15, 20, and 25 June 2007, encompassing the period when PMC's were observed in the Arctic region (E2008). The EXP1, EXP2, and EXP3 simulations all use the same sets of initial conditions.

We first examine the performance of CHEM2D-H2O using the UARS-based reference state (EXP1). Figure 9a plots the water vapor mixing ratio initial conditions for 00:00 UTC on 5 June 2007, which are based on the assimilation of Aura MLS Version 2.2 (V2.2) $\mathrm{H}_{2} \mathrm{O}$ profiles between 100$0.002 \mathrm{hPa}(\sim 16-90 \mathrm{~km})$ combined with CHEM2D model values of the $\mathrm{H}_{2} \mathrm{O}$ above the $0.002 \mathrm{hPa}$ level (see E2008 for details). Note that EXP1, EXP2, and EXP3 simulations all use the same sets of initial conditions. 

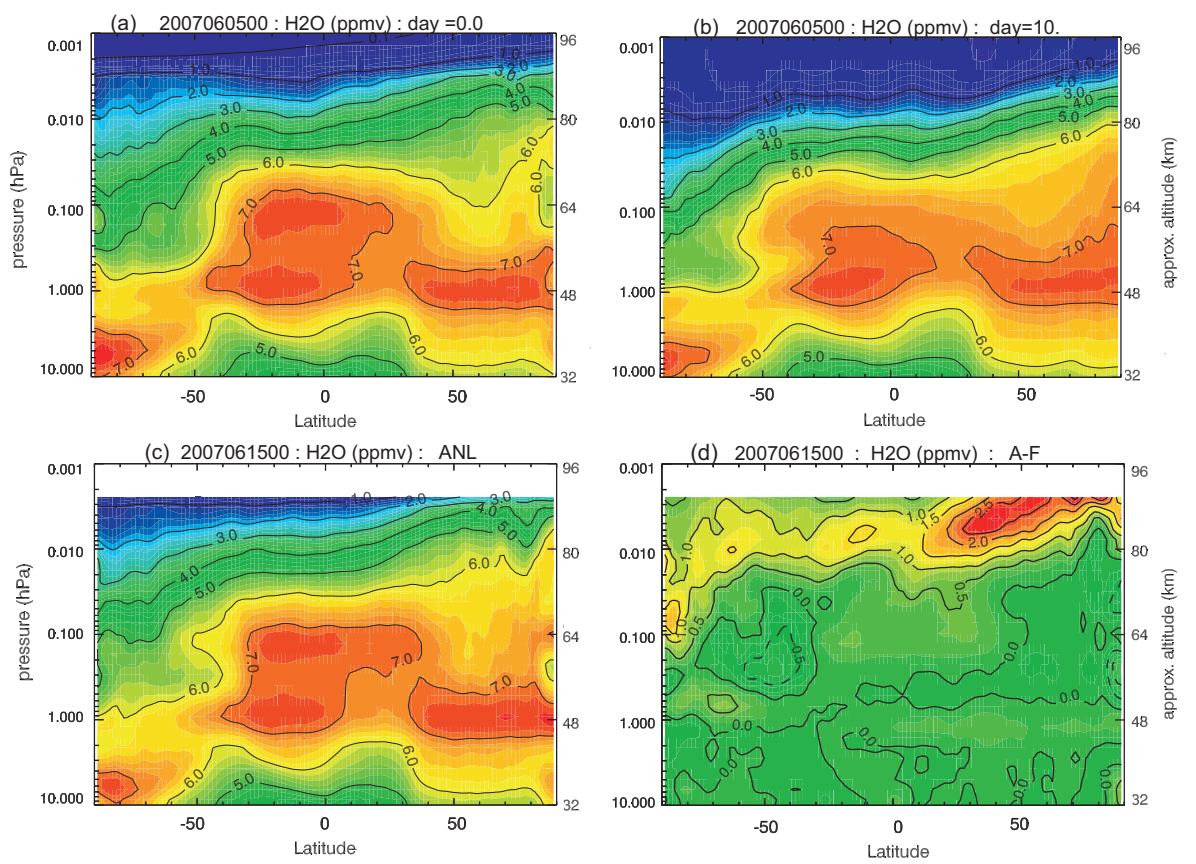

Fig. 9. Pressure-latitude plots of (a) NOGAPS-ALPHA analyzed zonal mean $\mathrm{H}_{2} \mathrm{O}$ mixing ratios for 00:00 UTC 5 June 2007 ; (b) zonal mean forecast model $\mathrm{H}_{2} \mathrm{O}$ mixing ratios at day 10 of the EXP1 model simulation initialized 00:00 UTC 5 June and valid 00:00 UTC 15 June 2007 (c) zonal mean NOGAPS-ALPHA analyzed $\mathrm{H}_{2} \mathrm{O}$ at 00:00 UTC on 15 June 2007; (d) differences in $\mathrm{H}_{2} \mathrm{O}$ mixing ratios between the 10-day forecast (F) in (b) and the analyzed (A) values in (c). Solid and dashed contours denote positive and negative differences, respectively.

Figure $9 \mathrm{~b}$ plots the model $\mathrm{H}_{2} \mathrm{O}$ mixing ratios on day 10 of the EXP1 simulation valid 15 June at 00:00 UTC. A comparison of Fig. 9b with Fig. 9a shows that the major differences in NOGAPS-ALPHA zonal mean $\mathrm{H}_{2} \mathrm{O}$ after 10 days are: (1) a decrease at all latitudes above the $0.01 \mathrm{hPa}$ level $(\sim 82 \mathrm{~km})$; (2) an increase near $0.1 \mathrm{hPa}(\sim 65 \mathrm{~km})$ poleward of $50^{\circ} \mathrm{N}$; (3) a decrease over high southern latitudes between $1.0-0.1 \mathrm{hPa}$. The high latitude changes are consistent with upwelling (downwelling) of moist (dry) air in the summer (winter) polar mesosphere. The broad decrease above the $0.01 \mathrm{hPa}$ level is the result of the parameterized photolysis of $\mathrm{H}_{2} \mathrm{O}$.

Figure 9c plots the zonal mean NOGAPS-ALPHA analyzed $\mathrm{H}_{2} \mathrm{O}$ mixing ratios valid on 00:00 UTC 15 June 2007. This and all following plots of analyzed $\mathrm{H}_{2} \mathrm{O}$ extend to $0.0025 \mathrm{hPa}$, which is the closest vertical level to the $0.002 \mathrm{hPa}$ upper limit for scientifically useful MLS $\mathrm{H}_{2} \mathrm{O}$ measurements (Froidevaux et al., 2006). Since NOGAPSALPHA analyzed $\mathrm{H}_{2} \mathrm{O}$ is completely constrained by the MLS measurements, the analyzed zonal mean values are essentially the same as a zonal mean estimated directly from the daily MLS data. Comparison of the analyzed $\mathrm{H}_{2} \mathrm{O}$ with the 10-day fields from EXP1 (Fig. 9b) shows large differences poleward of $30^{\circ} \mathrm{N}$ above the $0.01 \mathrm{hPa}$ level, where the analyzed values are much higher than the modeled values. Figure $9 \mathrm{~d}$ plots the differences between the zonal mean ana- lyzed $\mathrm{H}_{2} \mathrm{O}$ and 10-day forecast $\mathrm{H}_{2} \mathrm{O}$. After 10 days the EXP1 model simulation underestimates the zonal mean $\mathrm{H}_{2} \mathrm{O}$ mixing ratio throughout the northern extratropical upper mesosphere by more than 2 ppmv. This is the same region where the UARS-based and Aura MLS-based $r^{o}$ distributions differ substantially (Fig. 8), and where photolytic loss dominates (Fig. 3).

As mentioned in the previous section, the performance of the CHEM2D-H2O parameterization can be affected by the choice of the background reference state $r^{o}$ because it relaxes the forecast model $\mathrm{H}_{2} \mathrm{O}$ mixing ratios in the upper levels toward the reference state value $r^{o}$. In practice, the water vapor distribution used to represent $r^{o}$ should be chosen so as to avoid any systematic bias between the prognostic humidity variable and the assimilated humidity fields used to initialize and update the forecast system (see, e.g. Coy et al., 2007). Systematically low values of $r^{o}$, such as those seen in Fig. 8a, can lead to an overestimate of the $\mathrm{H}_{2} \mathrm{O}$ loss in the northern summer upper mesosphere. This may help explain why the 10-day EXP1 forecast underestimates the $\mathrm{H}_{2} \mathrm{O}$ mixing ratio compared to the analyses (Fig. 9d) in the northern extratropical upper mesosphere.

To investigate this possibility, we isolate the effect of parameterized water vapor photochemistry by taking the difference between the model mixing ratio $r$ and a passive humidity tracer $r_{\text {pass }}$, which uses the same initial conditions as $r$ 


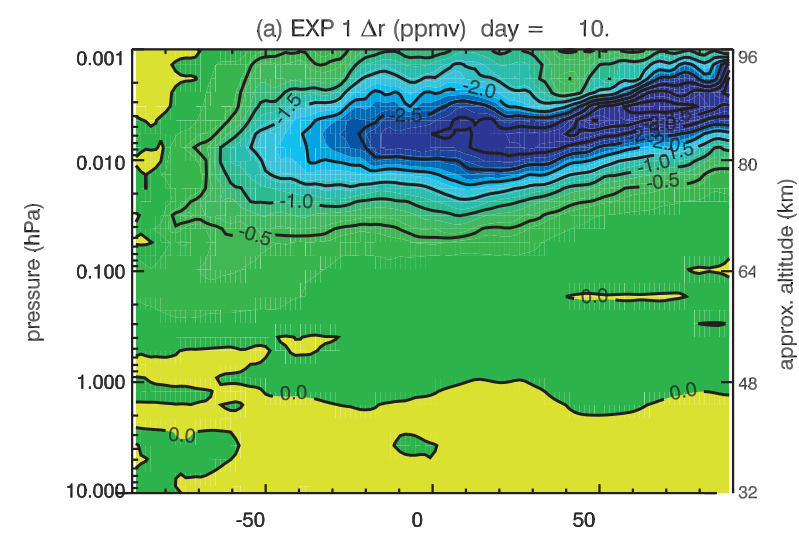

(b) EXP $2 \Delta r(p p m v)$ day $=10$.

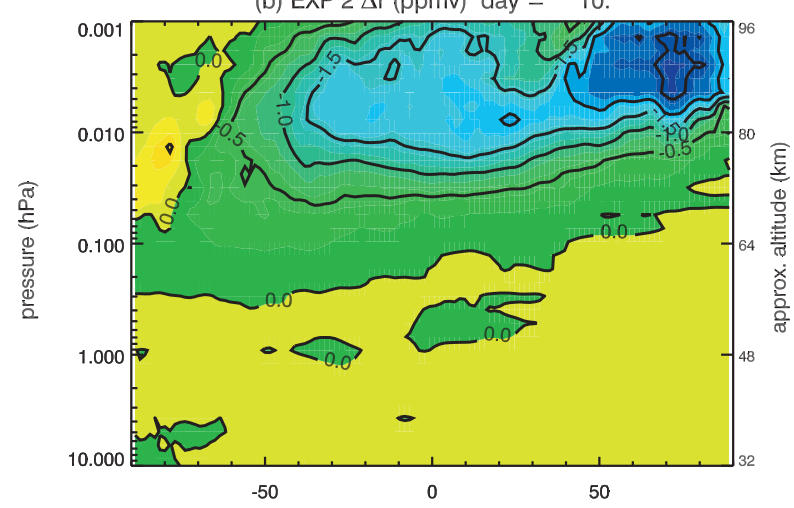

(c) EXP $3 \Delta r(p p m v)$ day $=10$.

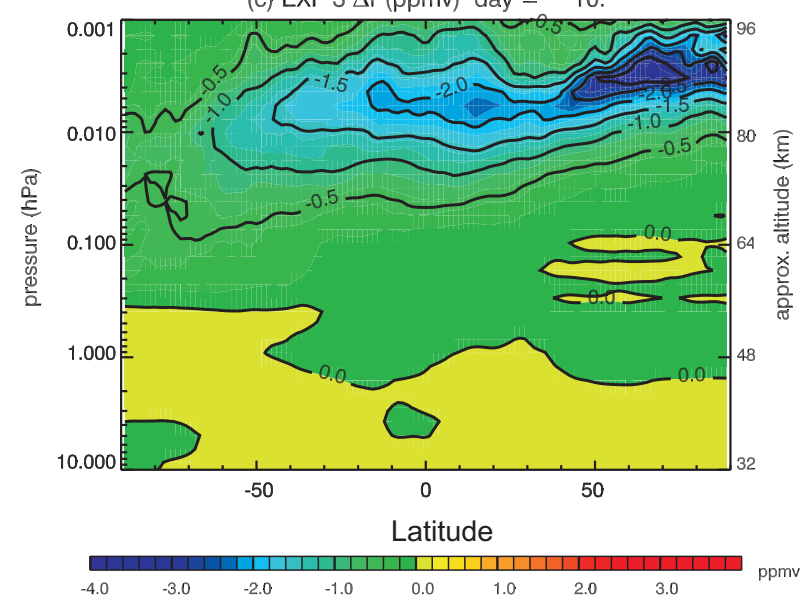

Fig. 10. Zonal mean values of $\Delta r$, the difference between NOGAPS-ALPHA model prognostic $\mathrm{H}_{2} \mathrm{O}$ and passive (i.e., no photochemistry) $\mathrm{H}_{2} \mathrm{O}$ on day 10 of the (a) EXP1, (b) EXP2, and (c) EXP3 simulations initialized 00:00 UTC 5 June 2007.

but is not subject to parameterized photochemistry and moist physics. In the troposphere and lowermost stratosphere, the lack of moist physics in the passive humidity field produces huge differences between $r$ and $r_{\text {pass }}$ (not shown). In the upper stratosphere and mesosphere, differences between $r$ and $r_{\text {pass }}$ are due primarily to the effect of the CHEM2D-H2O parameterized photochemistry acting on $r$.
Figure 10 plots zonal mean values of the difference $\Delta r=r-r_{\text {pass }}$ throughout the middle atmosphere on day 10 of EXP1, EXP2, and EXP3 simulations initialized 00:00 UTC 5 June 2007. In all three simulations, the effects of the parameterized photochemistry on the model $\mathrm{H}_{2} \mathrm{O}$ after 10 days are relegated to the upper mesosphere. Specifically, values of $\Delta r$ are negative throughout the Northern Hemisphere between $0.03-0.001 \mathrm{hPa}$, consistent with $\mathrm{H}_{2} \mathrm{O}$ loss via photolysis (e.g., Fig. 5) that peaks at high summer latitudes. The extension of negative values of $\Delta r$ across the equator and into the winter hemisphere is a consequence of photochemicallyprocessed air with lower mixing ratio $r$ being transported from the northern summer mesosphere to the southern winter hemisphere by the mean meridional circulation. Since the timescale for $\mathrm{H}_{2} \mathrm{O}$ production via $\mathrm{CH}_{4}$ oxidation is $>50$ days in most of the stratosphere (see Fig. 5), values of $\Delta r$ after 10 days in Fig. 10 are quite small in magnitude throughout the stratosphere.

Comparing the amount of photochemical loss among the three different simulations in Fig. 10, we find that the greatest amount of loss is produced in EXP1 (Fig. 10a). The amount of loss produced by CHEM2D-H2O is reduced in EXP2 when the UARS-based climatological values of $r^{o}$ are replaced with the Aura MLS monthly zonal mean $\mathrm{H}_{2} \mathrm{O}$ (Fig. 10b), particularly between the 0.01 and 0.001 pressure levels. Both EXP2 and EXP3 results show similar amounts of loss in the upper mesosphere at high northern latitudes. This indicates that both CHEM2D-H2O and ECMWF parameterizations produce comparable results in the region where peak $\mathrm{H}_{2} \mathrm{O}$ photolysis occurs. Figure $10 \mathrm{c}$ also indicates that the ECMWF parameterization used in EXP3 produces loss at high southern latitudes where no sunlight is present, unlike the CHEM2D-H2O results in EXP1 and EXP2.

To further characterize the performance of CHEM2D$\mathrm{H} 2 \mathrm{O}$ in NOGAPS-ALPHA, we compare 10-day forecast model $\mathrm{H}_{2} \mathrm{O}$ fields with analyzed $\mathrm{H}_{2} \mathrm{O}$ using five sets of simulations initialized 00:00 UTC on 5, 10, 15, 20, and 25 June 2007. Figure 11a plots vertical profiles of the global areaweighted mean difference between analyzed and forecast $\mathrm{H}_{2} \mathrm{O}$ mixing ratios (denoted "A-F") from all five sets. We find that the CHEM2D-H2O parameterization with UARSbased $r^{o}$ values in EXP1 produces the largest mean values of A-F above the $0.1 \mathrm{hPa}$ level, consistent with the excessive $\mathrm{H}_{2} \mathrm{O}$ loss seen in Fig. 10. In contrast, CHEM2D-H2O with Aura MLS-based $r^{o}$ values produces the smallest mean A-F values. This result holds true when we examine mean A$\mathrm{F}$ values over separate latitude bands between $90^{\circ} \mathrm{S}-90^{\circ} \mathrm{N}$ (Fig. 11b-f). Figure 11 also shows that the ECMWF scheme in EXP3 generally produces larger values of A-F than the CHEM2D-H2O scheme in EXP2, particularly in the southern extratropics (Fig. 11b and c). This is due to the fact that the ECMWF scheme specifies photolytic loss of $\mathrm{H}_{2} \mathrm{O}$ at the high southern (winter) latitudes despite the lack of sunlight. At high northern (summer latitudes) CHEM2D-H2O and ECMWF $\mathrm{H}_{2} \mathrm{O}$ results are comparable. 

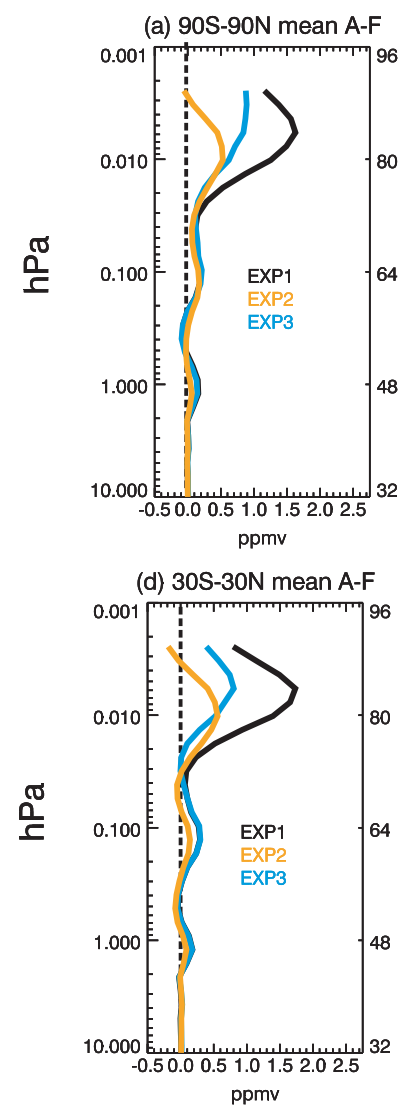
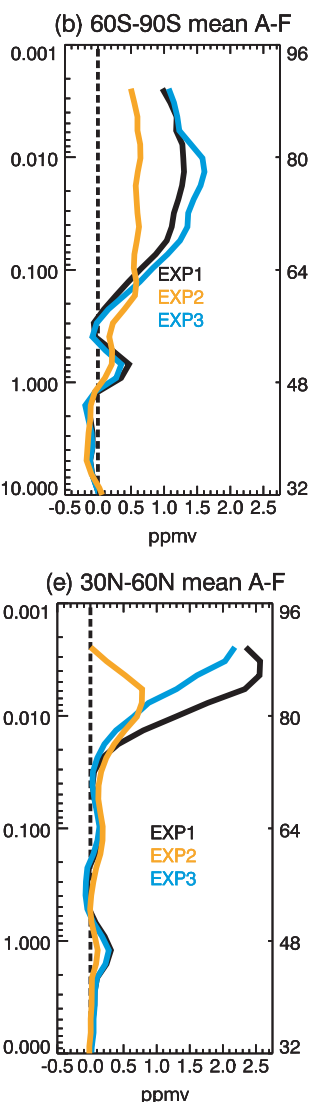
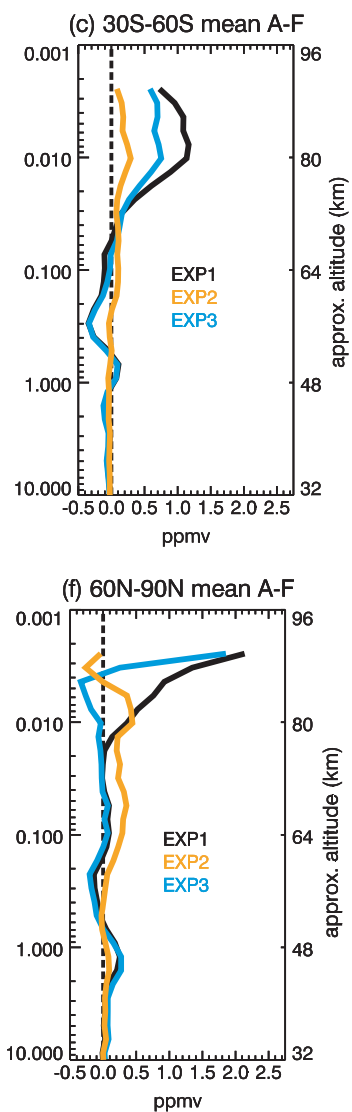

Fig. 11. Mean differences between NOGAPS-ALPHA analyzed $\mathrm{H}_{2} \mathrm{O}$ and 10-day forecast $\mathrm{H}_{2} \mathrm{O}(\mathrm{A}-\mathrm{F})$ based on forecast model simulations initialized 00:00 UTC on June 5, 10, 15, 20, and 25, 2007 using CHEM2D-H2O with UARS-based reference state (EXP1), CHEM2D$\mathrm{H} 2 \mathrm{O}$ with Aura MLS-based reference state (EXP2), and the ECMWF parameterization (EXP3). Results are presented for (a) the global area-weighted average A-F, (b) $60^{\circ} \mathrm{S}-90^{\circ} \mathrm{S}$, (c) $30^{\circ} \mathrm{S}-60^{\circ} \mathrm{S}$, (d) $30^{\circ} \mathrm{S}-30^{\circ} \mathrm{N}$, (e) $30^{\circ} \mathrm{N}-60^{\circ} \mathrm{N}$, and (f) $60^{\circ} \mathrm{N}-90^{\circ} \mathrm{N}$.

The preliminary evaluation of forecast model results for the June 2007 period indicates that all of the 10-day forecasts tend to underestimate the $\mathrm{H}_{2} \mathrm{O}$ mixing ratios in the northern extratropics (see Fig. 11e) compared to the analyzed MLS values above the $0.01 \mathrm{hPa}$ level, regardless of the details of the photochemistry parameterization. It should be noted that the Aura MLS accuracy limits ( $\pm 0.5 \mathrm{ppmv})$ and broad (12$16 \mathrm{~km}$ ) vertical resolution in the upper mesopheric $\mathrm{H}_{2} \mathrm{O}$ retrievals (Lambert et al., 2007) may complicate the evaluation of forecast skill in this region. It should also be noted that the forecast model transport in the upper mesosphere is highly sensitive to the details of the parameterized gravity wave drag, and that these details remain poorly constrained by observations. Because the effective $\mathrm{H}_{2} \mathrm{O}$ lifetime is comparable to transport timescales in the $0.1-0.01 \mathrm{hPa}$ region, deficiencies in model transport may contribute to some of the disagreement between the observations and the 10-day forecast model simulations. The effects of model transport in general, and gravity wave drag in particular, on NOGAPSALPHA middle atmospheric $\mathrm{H}_{2} \mathrm{O}$ simulations are currently under investigation.
Finally, to demonstrate the effect of the CHEM2D-H2O and ECMWF photochemistry parameterizations on stratospheric water vapor, where the relevant photochemical time scales are much longer than in the mesosphere, the EXP1 and EXP3 simulations were extended out to day 90. Figure 12 compares zonal mean $\Delta r$ values from EXP1 and EXP3 between $10-0.1 \mathrm{hPa}$ on day 90 . In general, we find that both schemes produce small increases in water vapor $(0.25$ $0.5 \mathrm{ppmv}$ ) in the tropical upper stratosphere. A notable result in Fig. 12 is that the CHEM2D-H2O scheme in EXP1 leads to relatively more photochemical loss of $\mathrm{H}_{2} \mathrm{O}$ in the mesosphere compared to the ECMWF scheme in EXP3 and thus a drier upper stratosphere over the South Pole due to downward transport of mesospheric air at high winter latitudes. This result suggests that using a $\mathrm{H}_{2} \mathrm{O}$ photochemistry parameterization with latitude and seasonal dependences may reduce the moist bias in mesospheric $\mathrm{H}_{2} \mathrm{O}$ seen in ECMWF analyses (Feist et al., 2007), and thereby improve its representation of dry mesospheric air descending into the polar vortex during winter and spring. To address this issue further, we plan to compare NOGAPS-ALPHA water vapor analyses 


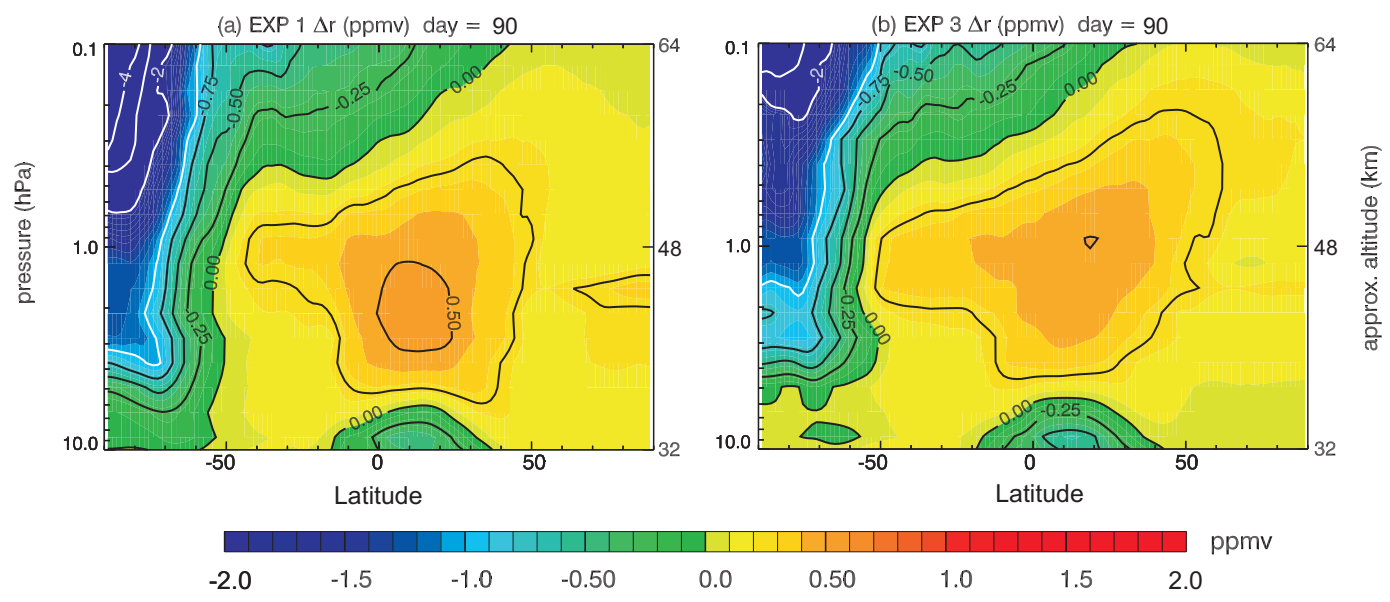

Fig. 12. Zonal mean values of the difference between NOGAPS-ALPHA prognostic $\mathrm{H}_{2} \mathrm{O}$ and passive $\mathrm{H}_{2} \mathrm{O}$ mixing ratio, $\Delta r$, on day 90 of (a) EXP1 and (b) EXP3 free-running NOGAPS-ALPHA forecast simulations initialized 00:00 UTC 5 June 2007.

from the full assimilations system using both the CHEM2D$\mathrm{H} 2 \mathrm{O}$ and ECMWF parameterizations over the course of the entire season.

\section{Conclusions}

We have described and tested the new CHEM2D-H2O parameterization for middle atmospheric water vapor photochemistry. CHEM2D-H2O is based on output from a zonally averaged (2-D) model with full photochemistry and accounts for the latitude, altitude, and seasonal dependences in the production and loss terms due to $\mathrm{CH}_{4}$ oxidation and $\mathrm{H}_{2} \mathrm{O}$ photolysis, respectively. The parameterization is valid up to lower thermospheric altitudes of $\sim 95-100 \mathrm{~km}$.

A series of 10-day NOGAPS-ALPHA forecast model simulations with parameterized $\mathrm{H}_{2} \mathrm{O}$ photochemistry were performed for the June 2007 period to evaluate the model's prognostic capability for middle atmospheric $\mathrm{H}_{2} \mathrm{O}$. The forecast model $\mathrm{H}_{2} \mathrm{O}$ mixing ratios were compared with NOGAPSALPHA analyzed $\mathrm{H}_{2} \mathrm{O}$ fields based on assimilation of Aura MLS profile measurements. We find that the CHEM2D-H2O and ECMWF parameterizations both perform comparably at all altitudes below the $0.1 \mathrm{hPa}$ level. Above this level, we find that CHEM2D-H2O performance is dependent on the choice of the reference state mixing ratio distribution. In the June 2007 case examined here, using CHEM2D-H2O with a reference state mixing ratio distribution based on the monthly zonal mean Aura MLS $\mathrm{H}_{2} \mathrm{O}$ from the June 2005-2008 period produced the best overall agreement with the analyses. Middle atmospheric water vapor mixing ratios were lower in the early 1990's and exhibited significant positive trends during the UARS time period (e.g., Nedoluha et al., 1998; Randel et al., 1999). Therefore it is not surprising that the use of the UARS $\mathrm{H}_{2} \mathrm{O}$ climatology to specify $r^{o}$ in EXP1 leads to a systematic underprediction for the June 2007 period analyzed here.

These preliminary results show that the latitude and seasonal dependences of the CHEM2D-H2O parameterization can offer an improved 10-day forecast of upper mesospheric water vapor compared to the 1-D parameterization currently used in some operational NWP/DA systems. We are now carrying out a more formal evaluation of middle atmospheric $\mathrm{H}_{2} \mathrm{O}$ prognostic skill in NOGAPS-ALPHA over a longer time period using the fully coupled NWP/DA system, which will provide a more complete and objective assessment of CHEM2D-H2O performance. Future work will combine NOGAPS-ALPHA prognostic $\mathrm{H}_{2} \mathrm{O}$ and temperature fields in order to predict supersaturation conditions that lead to the formation of polar mesospheric clouds. The role of additional physical processes such as molecular diffusion, which is not currently accounted for in either the CHEM2D or NOGAPS-ALPHA model, will also be investigated.

The CHEM2D-H2O parameterization is freely available for research purposes. For more details, please contact the lead author.

Acknowledgements. The authors thank S. D. Eckermann and the two referees for their valuable comments and discussions. We also wish to thank the EOS Aura MLS team and the TIMED SABER team. This work was supported in part by grants from the Office of Naval Research and from the National Aeronautics and Space Administration under Grant No. NNH08AI67I issued through the Heliophysics Theory Program. NOGAPS-ALPHA simulations were made possible by a grant of computer time from the DoD High Performance Computing Modernization Program at the U.S. Air Force Research Laboratory.

Edited by: W. Lahoz 


\section{References}

Brasseur, G. and Solomon, S.: Aeronomy of the Middle Atmosphere, 2nd ed., D. Reidel, Norwell, MA, USA, 452 pp., 1986.

Cariolle, D. M. and Dèqué: Southern hemisphere medium-scale waves and total ozone disturbances in a spectral general circulation model, J. Geophys. Res., 91, 10 825-10 846, 1986.

Coy, L., Allen, D. R., Eckermann, S. D., McCormack, J. P., Stajner, I., and Hogan, T. F.: Effects of model chemistry and data biases on stratospheric ozone assimilation, Atmos. Chem. Phys., 7, 2917-2935, 2007, http://www.atmos-chemphys.net/7/2917/2007/.

Eckermann, S. D., Hoppel, K. W., Coy, L., McCormack, J. P., Siskind, D. E., Nielsen, K., Kochenash, A., Stevens, M. H., and Englert, C. R.: High-altitude data assimilation system experiments for the Northern Hemisphere summer mesosphere season of 2007, J. Atmos. Sol. Terr. Phys., doi:10.1016/j.jastp.2008.09.036, in press, 2008.

European Center for Medium-Range Weather Forecasts Integrated Forecast System Documentation Cy31r1, Part IV: Physical Processes, online available at: http://www.ecmwf.int/research/ ifsdocs/CY31r1/PHYSICS/IFSPart4.pdf, 2007.

Feist, D. G., Geer, A. J., Müller, S., and Kämpfer, N.: Middle atmosphere water vapour and dynamical features in aircraft measurements and ECMWF analyses, Atmos. Chem. Phys., 7, 52915307, 2007, http://www.atmos-chem-phys.net/7/5291/2007/.

Froidevaux, L., Livesey, N. J., Read, W. G., Jiang, Y. B., Jimenez, C., et al.: Early validation analyses of atmospheric profiles from EOS MLS on the Aura satellite, IEEE T. Geosci. Remote Sens., 44, 1106-1121, 2006.

Garcia, R. R., Marsh, D. R., Kinnison, D. E., Sassi, F., and Boville, B. A.: Simulation of secular trends in the middle atmosphere, J. Geophys. Res., 112, D09301, doi:10.1029/2006JD007485, 2007.

Geer, A. J., Lahoz, W. A., Jackson, D. R., Cariolle, D., and McCormack, J. P.: Evaluation of linear ozone photochemistry parametrizations in a stratosphere-troposphere data assimilation system, Atmos. Chem. Phys., 7, 939-959, 2007,

http://www.atmos-chem-phys.net/7/939/2007/.

Grooß, J.-U. and Russell, J. M.: Technical note: A stratospheric climatology for $\mathrm{O}_{3}, \mathrm{H}_{2} \mathrm{O}, \mathrm{CH}_{4}, \mathrm{NO}_{x}, \mathrm{HCl}$ and $\mathrm{HF}$ derived from HALOE measurements, Atmos. Chem. Phys., 5, 2792-8207, 2005, http://www.atmos-chem-phys.net/5/2792/2005/.

Harich, S. A., Hwang, D. W. H., Yang, X., Lin, J. J., Yang, X., and Dixon, R. N.: Photodissociation of $\mathrm{H} 2 \mathrm{O}$ at $121.6 \mathrm{~nm}$ : A state-tostate dynamical picture, J. Chem. Phys., 113, 22, 2000.

Hogan, T. and Rosmond, T.: The description of the Navy Operational Global Atmospheric Prediction System's spectral forecast model, Mon. Wea. Rev., 119, 1186-1815, 1991.

Hoppel, K. W., Baker, N. L., Coy, L., Eckermann, S. D., McCormack, J. P., Nedoluha, G., and Siskind, D. E.: Assimilation of stratospheric and mesospheric temperatures from MLS and SABER into a global NWP model, Atmos. Chem. Phys., 8, 6103-6116, 2008, http://www.atmos-chemphys.net/8/6103/2008/.

Kutepov A. A., Feofilov, A. G., Marshall, B. T., Gordley, L. L., Pesnell,W. D., Goldberg, R. A., and Russell, J. M.:, SABER temperature observations in the summer polar mesosphere and lower thermosphere: Importance of accounting for the $\mathrm{CO}_{2}$ $\nu_{2}$ quanta V-V exchange, Geophys. Res. Lett., 33, L21809, doi:10.1029/2006GL026591, 2006.
Lambert, A., Read, W. G., Livesey, N. J., Santee, M. L., Manney, G. L., et al.: Validation of the Aura Microwave Limb Sounder middle atmospheric water vapor and nitrous oxide measurements, J. Geophys. Res., 112, D24S36, doi:10.1029/2007JD008724, 2007.

Lahoz, W. A., Errera, Q., Swinbank, R., and Fonteyn, D.: Data assimilation of stratospheric constituents: A review, Atmos. Chem. Phys., 7, 5745-5773, 2007, http://www.atmos-chemphys.net/7/5745/2007/.

Lean, J., Rottman, G., Kyle, H., Woods, T., Hickey, J., and Puga, L.: Detection and parameterization of variations in solar midand near-ultraviolet radiation $(200-400 \mathrm{~nm})$ : J. Geophys. Res., 102, 29939-29956, 1997.

Lewis, B. R., Vardava, I. M., and Carver, J. H.: The aeronomic dissociation of water vapor by solar H Lyman a radiation, J. Geophys. Res., 88, A6, 4935-4940, 1983.

LeTexier, H., Solomon, S., and Garcia, R. R.: the role of molecular hydrogen and methane oxidation in the water vapour budget of the stratosphere, Q. J. R. Meteorol. Soc., 114, 281-295, 1988.

MacKenzie, I. A. and Harwood, R. S.: Middle atmospheric response to a future increase in humidity arising from increased methane abundance, J. Geophys. Res., 109, D02107, doi:10.1029/2003JD003590, 2004.

McCormack, J. P., Eckermann, S. D., Coy, L., et al.: NOGAPSALPHA model simulations of stratospheric ozone during the SOLVE2 campaign, Atmos. Chem. Phys., 4, 2401-2423, 2004, http://www.atmos-chem-phys.net/4/2401/2004/.

McCormack, J. P., S. D. Eckermann, D. E. Siskind, and T. J. McGee, CHEM2D-OPP: A new linearized gas-phase ozone photochemistry parameterization for high-altitude NWP and climate models, Atmos. Chem. Phys., 6, 4943-4972, 2006, http://www.atmos-chem-phys.net/6/4943/2006/.

McCormack, J. P., Siskind, D. E., and Hood, L. L.: Solar-QBO interaction and its impact on stratospheric ozone in a zonally averaged photochemical transport model of the middle atmosphere, J. Geophys. Res., 112, D16109, doi:10.1029/2006JD008369, 2007.

Minschwaner, K., Salawitch, R. J., and McElroy, M. B.: Absorption of solar radiation by $\mathrm{O}_{2}$ : Implications for $\mathrm{O}_{3}$ and lifetimes of $\mathrm{N}_{2} \mathrm{O}, \mathrm{CFCCl} 3$, and CF2Cl2, J. Geophys. Res., 98, $10543-$ $10561,1993$.

Nedoluha, G., Bevilacqua, R., Gomez, R., Siskind, D., Hicks, B., Russell, J., and Connor, B., Increases in middle atmospheric water vapor as observed by the Halogen Occultation Experiment and the ground-based Water Vapor Millimeter-wave Spectrometer from 1991-1997, J. Geophys. Res., 103, D3, 3531-3543, 1998.

Peng, M. S., Ridout, J. A., and Hogan, T. F.: Recent modifications of the Emanuel convective scheme in the Navy Operational Global Atmospheric Prediction System, Mon. Weather Rev., 132, 1254-1268, 2004.

Randel, W. J., Wu, F., Russel, J. M., Roche, A., and Waters, J. W.: Seasonal cycles and QBO variations in stratospheric $\mathrm{CH}_{4}$ and $\mathrm{H}_{2} \mathrm{O}$ observed in UARS HALOE data, J. Atmos. Sci., 55, 163$185,1998$.

Randel, W. J., Wu, F., Russell, J. M., and Waters, J.: Space-time patterns of trends in stratospheric constituents derived from UARS measurements, J. Geophys. Res., 104, D3, 3711-3727, 1999.

Sander, S. P., Friedl, R. R., Ravishankara, A. R., et al.: Chemical kinetics and photochemical data for use in atmospheric stud- 
ies, Evaluation No. 14, Jet Propulsion Laboratory, Pasadena, CA, USA, 334 pp., 2003.

Siskind, D. E., Eckermann, S. D., McCormack, J. P., et al.: Hemispheric differences in the temperature of the summertime stratosphere and mesosphere, J. Geophys. Res., 108(D2), 4051, doi:10.1029/2002JD002095, 2003.

Siskind, D. E., Minschwaner, K., and Eckman, R. S.: Photodissociation of $\mathrm{O} 2$ and $\mathrm{H} 2 \mathrm{O}$ in the middle atmosphere: Comparison of numerical methods and impact on model $\mathrm{O}_{3}$ and $\mathrm{OH}$, Geophys. Res. Lett., 21(10), 863-866, 1994.

Slingo, J. M.: The development and verification of a cloud prediction scheme in the ECMWF model, Q. J. R. Meteorol. Soc., 113, 899-927, 1987.

Stief, L., J., Payne, W. A., and Klemm, R. B.: A flash photolysisresonance fluorescence study of the formation of $\mathrm{O}(1 \mathrm{D})$ in the photolysis of water and the reaction of $\mathrm{O}(1 \mathrm{D})$ with $\mathrm{H} 2$, Ar, and He, J. Chem. Phys., 62(10), 4000-4008, 1975.
Summers, M. E., Siskind, D. E., Bacmeister, J. T., Conway, R. R., Zasadil, S. E., and Strobel, D. F.: Seasonal variation of middle atmospheric $\mathrm{CH}_{4}$ and $\mathrm{H}_{2} \mathrm{O}$ with a new chemical-dynamical model, J. Geophys. Res., 102, 3503-3526, 1997.

Teixeira, J. and Hogan, T.:, Boundary layer clouds in a global atmospheric model: Simple cloud cover parameterization, J. Climate, 15, 1261-1276, 2002.

Tiedtke, M.: The sensitivity of the time-scale flow to cumulus convection in the ECMWF model, Proceedings from the Workshop on Large-Scale Numerical Models, European Centre for Medium-Range Weather Forecasts, Reading, UK, 28 November1 December 1983, 297-316, 1984.

Untch, A. and Simmons, A. J.: Increased stratospheric resolution in the ECMWF forecasting system, ECMWF Newsletter No. 82, online available at: http://www.ecmwf.int/publications/ newsletters/pdf/82.pdf, 1999. 